\section{New York City Museum of Science and Industry}

THE New York City Museum of Science and Industry was formally opened on the evening of February 11 in a novel manner. At 3.35 a.m. G.M.T. on February 12 (10.35 p.m. February 11, in New York), Sir William Bragg was seated in Faraday's old study at the Royal Institution before the table at which Faraday used to work; and he gave a short address to a distinguished gathering in the New York Museum, including Prof. Albert Einstein, Dr. F. B. Jewett of the Bell Telephone Laboratories, and the Mayor of New York. The American listeners then heard Sir William strike a match, with which he lit an old candle set in a candle-stick of Faraday's time; in a few instants, the entrance hall of the New York Museum was flooded with the light of two rows of mercury vapour lamps. The means by which this feat was accomplished provides an interesting demonstration of one of the many marvellous attainments of modern applied science which have resulted from Faraday's pioneer work of more than a hundred years ago. When Sir William lit the candle, the light was incident on a photo-electric cell, and the resulting electrical impulse was amplified and transmitted over telephone lines to the Post Office trans-Atlantic radio station at Rugby. The signal passing over the radio link was received at Netrong, U.S.A., by the American Telephone and Telegraph Company's station, and then re-transmitted by telephone line to the New York Museum of Science and Industry, where it was made to light a Westinghouse lamp of fifty years ago. The light from this lamp was picked up by another photo-electric cell, which in turn actuated the switches controlling the mercury vapour lamps flood-lighting the hall of the Museum.

In the course of his address, which was relayed in America by the National Broadcasting Company, Sir William Bragg referred to the first description of an ideal science museum and its uses, written by the American, Benjamin Thomson, Count Rumford, some hundred and forty years ago. The first attempt to carry out Rumford's plan was made in the Royal Institution of Great Britain, but was a failure. It remained for Sir Humphry Davy to see other opportunities for the Royal Institution and to mould its activities so that it became a school of research and a platform from which the results of scientific progress could be described to the public. Here worked Faraday, whose scientific discoveries have done more perhaps than those of any other man to influence modern thought and modern ways. It was very appropriate that the modern achievements of electrical science, the foundations of which were laid by Faraday, should be employed in the manner described above to open another science museum. The work of this museum would prove most valuable in interpreting for the common good the triumphs of the past and the hopes of the future in the realm of science. In conclusion, Sir William prayed that this new Museum of Science and Industry might go forward steadily and strongly in its task of education and conciliation, and help in its own way to lead men into the paths of unity and peace.

\section{Radioactivity and Atomic Structure}

The Faraday Lecture to the Chemical Society was given at the Royal Institution on February 12 by Lord Rutherford. The title was "Radioactivity and Atomic Structure"; but Lord Rutherford, rightly, was less concerned with discussing the latest results in nuclear transformations than with giving a general account of the development of radioactivity in the past forty years, and relating its discoveries to the theories and ideas of the chemist. The personal note of the lecture was greatly appreciated by the audience. Lord Rutherford began by giving an account of his own work at Cambridge and Montreal in the early days, of the discovery of the emanating power of thorium, of the characteristic rate of decay of the emanation, of its odd power of 'exciting' or 'inducing' radioactivity in neighbouring solids, and the other work which led to the disintegration theory of Rutherford and Soddy in 1902-3. This was the first sustained attack on the chemist's concept of the atom as a solid and permanently stable structure, and the first hint that an explanation might be found some day for the existence of the periodic classification. He passed then to the great period 1911-13 when the nuclear theory of the atom was established, the group-displacement was put forward, and physicists and chemists were reluctantly compelled to believe in the existence of isotopes-at least for the heaviest elements.

Work since the Great War both on the nucleus and on isotopes has gone from strength to strength. In 1919, artificial disintegration of light elements by one of the spontaneous disintegration products was clearly established. Great developments since then have become possible by the discovery of powerful electrical methods for producing streams of bombarding projectiles and by improvements in automatic methods for counting particles. In some cases, rare, but stable and already known, isotopes have been produced; in others, atoms have been artificially made which show both old and new forms of radioactivity. Concurrently with this work the massspectrograph has revealed the complexity of the majority of elements and determined accurately the masses of the isotopes. Some of these accurate results have been of great importance in establishing the principle of the conservation of energy in many nuclear reactions and generally in revealing the structure of the nucleus. Results like these have been a very notable contribution to one of the problems which Faraday, in his day, considered lay before chemists : "to decompose the metals, to reform them and to realize the once absurd notion of transmutation". Lord Rutherford ended by pointing out that much still remains to be done before we can hope to understand how atoms have been built up of elementary particles or grasp the significance of the relative abundance of the different atoms on our earth.

\section{The Huxley Letters}

IN the history of scientific thought there have been a few supreme occasions only on which scientific men have been compelled to enter the public lists 